genetic associations may be masked by ethnic heterogeneity and, with age, by the increasing impact of hormonal and environmental factors.

1 Tikkanen MJ. Immunogenetic polymorphism of apolipoprotein B in man. Studies with a monoclonal anti- $\mathrm{Ag}(\mathrm{c})$ antibody. Am Heart f 1987;113:462-7.

2 Viikari J, Ákerblom HK, Nikkari T, et al. Atherosclerosis precursors in Finnish children and adolescents. IV. Serum lipids in newborns, children and adolescents. Acta Paediatr Scand $1985 ; 318$ (suppl): $103-9$.

3 Berg K. DNA polymorphism at the apolipoprotein B locus is associated with lipoprotein level. Clin Genet 1986;30:515-20.

4 Talmud PJ, Barni N, Kessling AM, et al. Apolipoprotein B gene variants are involved in the determination of serum cholesterol levels: a study in normo- and hyperlipidaemic individuals. Atherosclerosis 1987;67:81-9.

5 Young SG, Bertics SJ, Scott TM, et al. Apolipoprotein B allotypes $M B 19_{1}$ and $M B 19_{2}$ in subjects with coronary artery disease and hypercholesterolemia. Arteriosclerosis 1987;7:61-5.

(Accepted 14 October 1987)

Third Department of Medicine, Meilahti Hospital, University of Helsinki, 00290 Helsinki

$M \mathrm{~J}$ TIKKANEN, MD, acting associate professor

Department of Medicine, University of Turku

J VIIKARI, MD, associate professor

Children's Hospital, University of Helsinki

H K ̊̊KERBLOM, MD, professor, II department of paediatrics

E PESONEN, MD, paediatric cardiologist, I department of paediatrics

Correspondence to: Dr Tikkanen.

\section{Transporting critically ill patients by ambulance: audit by sickness scoring}

Patients who are critically ill may be safely transported by specialist teams ${ }^{1}$ but no prospective studies to investigate the efficacy of transporting such patients by ordinary ambulances attended by junior doctors have been reported. Such studies are important because most critically ill patients are probably transported in this way. Financial constraints may result in increasing use of ordinary ambulances to transfer such patients to centralised units. We performed an audit of non-specialist transport within a district general hospital group in which a sickness score was used to control for severity of illness.

\section{Patients, methods, and results}

Vascular and general surgery, coronary care, and most medical specialties are sited within a five mile radius of this intensive care unit; patients are therefore commonly transferred to the unit by ambulances, the journey taking a maximum of 30 minutes. The unit accepts all patients except those with uncomplicated head injuries.

We studied 50 consecutive patients transferred to the unit. Severity of illness was assessed with a sickness score, ${ }^{1}$ which is a modification of the acute physiology and chronic health evaluation (APACHE II) score. ${ }^{2}$ The sickness score was calculated from data collected immediately before and after transport. Arterial blood samples for blood gas analysis were taken before transport, packed in ice, and analysed together with a sample drawn on arrival. Patients were not monitored during the journey. Controlled ventilation was provided with an Ambu bag; patients who had not been intubated received a controlled supply of oxygen from MC facemasks. The partial pressure of inspired oxygen was measured with an oxygen meter. Complications occurring during transfer and the seniority and specialty of the medical attendant were noted. Survival was taken as discharge home.

Of the 50 patients, 31 had had operations and 19 had medical conditions (repair of an aortic aneurysm 13; acute renal failure, 12; sepsis, seven; cardiac arrest, five; and respiratory problems, 13). Seven patients, three of whom had had operations, developed eight serious complications during transfer: obstruction of an endotracheal tube, respiratory arrest on arrival at the hospital, accidental disconnection of arterial and central venous cannulas, withdrawal of crucial inotropic and bronchodilator infusions (two cases), and unrecordable blood pressure on arrival (three). Six of the seven patients were attended by junior staff (registrar grade or below) who were not anaesthetists $\left(\chi^{2}=10.79, p<0.005\right)$.

The table shows the numbers of patients and their mean sickness scores before and after transfer. The difference in scores between the survivors and nonsurvivors was highly significant $(p<0.0001)$. The mean score for non-survivors showed a small increase after transport, though this was not significant. Patients who suffered complications and those accompanied by junior staff or staff other than anaesthetists tended to have higher scores, but the differences were not significant.
Sickness scores (and 95\% confidence intervals) before and after transport categorised by outcome, grade and specialty of attending staff, and complications

\begin{tabular}{lccc}
\hline & No of & \multicolumn{2}{c}{ Mean sickness score } \\
\cline { 3 - 4 } & patients & \multicolumn{1}{c}{ Before transport } & After transport \\
\hline Survivors & 34 & $10 \cdot 2(8 \cdot 9$ to $12 \cdot 0)$ & $10 \cdot 4(9 \cdot 1$ to $12 \cdot 2)$ \\
Non-survivors & 16 & $19 \cdot 0(16 \cdot 3$ to $21 \cdot 6)$ & $20 \cdot 6(17 \cdot 7$ to $23 \cdot 4)$ \\
Senior staff & 27 & $12 \cdot 0(9 \cdot 7$ to $14 \cdot 3)$ & $12 \cdot 5(10 \cdot 3$ to $14 \cdot 7)$ \\
Junior staff & 23 & $14 \cdot 1(11 \cdot 3$ to $16 \cdot 9)$ & $15 \cdot 0(11 \cdot 8$ to $18 \cdot 2)$ \\
Anaesthetists & 34 & $12 \cdot 4(10 \cdot 5$ to $14 \cdot 4)$ & $13 \cdot 0(11 \cdot 0$ to $15 \cdot 0)$ \\
Other & 16 & $14 \cdot 1(10 \cdot 4$ to $17 \cdot 9)$ & $15 \cdot 1(10 \cdot 8$ to $19 \cdot 3)$ \\
Complications & 7 & $15 \cdot 2(10 \cdot 1$ to $20 \cdot 4)$ & $16 \cdot 5(10 \cdot 2$ to $22 \cdot 9)$ \\
No complications & 43 & $12 \cdot 6(10 \cdot 7$ to $14 \cdot 5)$ & $13 \cdot 2(11 \cdot 2$ to $15 \cdot 2)$ \\
\hline
\end{tabular}

\section{Comment}

This study showed that life threatening complications may occur in critically ill patients when conventional ambulances are used for transport. Complications were more common in patients attended by junior doctors and doctors other than anaesthetists and were not due to more severe illness among these patients. The training in resuscitation received by anaesthetists may be an advantage in caring for patients when monitoring is not available. The complications were not the direct cause of death in any patient, probably because of the short journey; longer transport times might have resulted in a significant increase in sickness scores.

Because severity of illness was controlled for, these results suggest that inexperience in the management of patients who are critically ill is the dominant factor in the development of complications during transfer, confirming earlier work. ${ }^{3}$ The results support the need for improved training in resuscitation ${ }^{4}$ and suggest that blood pressure should be monitored during transfer.

1 Bion JF, Edlin SA, Ramsay G, McCabe S, Ledingham IMcA. Validation of a prognostic score in critically ill patients undergoing transport. Br Med f 1985;291:432-4.

2 Knaus WA, Draper EA, Wagner DP, Zimmerman JE. APACHE II: a severity of disease classification system. Crit Care Med 1985;13:818-29.

3 Waddell G, Scott PDR, Lees NW, Ledingham IMcA. Effects of ambulance transport in critically ill patients. Br Med f 1975; ;:386-9.

4 Baskett PJF. Resuscitation needed for the curriculum? Br Med f 1985;290:1531-2.

(Accepted 30 September 1987)

Intensive Care Unit, Plymouth General Hospital, Plymouth PL4 8QQ

J F BION, MRCP, FFARCS, senior registrar

I H WILSON, FFARCS, registrar

PA TAYLOR, FFARCS, consultant

Correspondence to: Dr J F Bion, Department of Anaesthetics, Birmingham University, Birmingham B15 2TH.

\section{Is altered cardiac sensation responsible for chest pain in patients with normal coronary arteries? Clinical observation during cardiac catheterisation}

Most patients with chest pain characterised as angina pectoris have obstructive atheromatous disease of the coronary arteries. In a few patients with angina pectoris exercise testing indicates abnormalities but coronary angiograms are normal. ${ }^{1}$ Various theories have been proposed to explain these findings, termed syndrome $\mathrm{X}$, and which include abnormalities of coronary reserve or myocardial metabolism and abnormal histological appearances..$^{2-4}$ During routine cardiac catheterisation we observed that patients with syndrome $X$ were unusually sensitive to intracardiac instrumentation. We report the findings of a preliminary study.

\section{Patients, methods, and results}

We studied seven patients with syndrome $\mathrm{X}$ (exertional chest pain associated with ST segment depression of more than $1 \mathrm{~mm}$ during exercise and normal coronary arteries); four patients with typical angina but negative results on exercise testing and normal coronary arteries; seven patients with atherosclerotic coronary artery disease; and nine patients with mitral valve disease. 